\title{
Uma visão contemporânea da avaliação psicológica para os contextos educativo e psicossocial
}

\author{
Juliana Maximila dePaula Bueno- UnivesidadeSãoFranasọ, Itatiba, SãoPaulo Brasil
}

Boruchovitch, E., Santos, A. A. A., \& Nascimento, E. (O rgs.). (2012). Avaliação psicoógica nos contextos elucativo e psicosscial. São Paulo: Casa do Psicólogo.

É evidente que o uso de testes psicológicos vem crescendo no país conjuntamente com a preocupação e busca por investigar as qualidades psicométricas de tais instrumentos. Esses aspectos se fazem presente na literatura atual, o que é pertinente para consolidar uma política de avaliação em Psicologia. Sob essa perspectiva, esse livro foi organizado por Evely Boruchovitch, Acácia Aparecida Angeli dos Santos e Elizabeth do Nascimento com o objetivo de apresentar o estado da arte da avaliação psicológica em âmbito nacional e internacional. A obra contém treze capítulos acerca da avaliação para os contextos educativo e psicossocial, dispostos em duas partes.

A primeira parte do livro refere-se às pesquisas no contexto educacional. Assim, no capítulo inicial, "A quarta edição das escalas Wechsler de Inteligência", Vera Lúcia Marques de Figueiredo, Francisco Antonio Soto Vidal e Elizabeth do Nascimento apresentam a nova composição e as características da estrutura fatorial dos instrumentos WISC-IV e WAIS-IV, que são utilizados para a mensuração de inteligência de crianças e adultos, respectivamente. Também fazem a comparação entre a versão mais atual dos instrumentos a terceira versão, que é a utilizada por profissionais brasileiros, e descrevem a fundamentação teórica subjacente. Os autores objetivam informar e atualizar profissionais e a comunidade acadêmica sobre esses dois importantes instrumentos para mensuração da inteligência, que nos próximos anos estarão disponíveis no Brasil.

As terminologias e conceituações utilizadas para dotação e talento ainda são controversas, o que implica a identificação e desenvolvimento de pessoas com essas características. Assim, no segundo capítulo, "Medidas de dotação e talento: produção científica em Psicologia (2006-2011)", Altemir José Gonçalves Barbosa, Patrícia Waltz Schelini e Lara Carolina de Almeida expõem sobre a disparidade da conceituação desses termos. É apresentado um panorama das publicações científicas internacionais e nacionais, sobre os construtos dotação e talento, em um estudo de levantamento realizado em publicações no período de cinco anos. Os autores evidenciam a escassez de estudos nacionais e concluem que a literatura brasileira sobre esse tema está aquém do estado da arte no âmbito internacional.
Sabe-se que no contexto educacional as estratégias de aprendizagem são de grande relevância como ferramenta para a compreensão dos estudantes ante as demandas escolares. No terceiro capítulo, "Estratégias de aprendizagem no Ensino Fundamental: revisando instrumentos de medida", Maria Gislaine Marques Perassinoto, Evely Boruchovitch e Katya Luciane de Oliveira apresentam instrumentos internacionais e nacionais acerca das estratégias de aprendizagem, indicando avanços e lacunas para futuros trabalhos.

No quarto capítulo, "Metacognição e monitoramento metacognitivo: das definições originais ao momento atual", Marília Zampieri, Patrícia Waltz Schelini e Jussara Fatima Pascualon definem o conceito de metacognição e enfatizam um dos seus principais componentes, 0 monitoramento. As autoras apresentam pesquisas, selecionadas por meio de estudos históricos, para assinalar o momento atual dos construtos, além de descreverem as principais técnicas internacionais e nacionais, considerando os desafios de mensuração dedicados à avaliação do monitoramento metacognitivo.

Avaliação da leitura e escrita em crianças é o tema do quinto capítulo, elaborado pelas autoras Adriana Cristina Boulhoça Suehiro e Neide de Brito Cunha, intitulado "Avaliação da leitura e da escrita em crianças: produção científica brasileira da primeira década de 2000 ". Elas realizaram uma pesquisa de levantamento da produção científica entre os anos de 2000 e 2009 sobre a avaliação da leitura e escrita em crianças. São apresentados, também, os instrumentos mais frequentemente utilizados para tal avaliação e suas propriedades psicométricas. Em seguida são feitos alguns apontamentos importantes de desafios e direções para novas pesquisas.

Atualmente o bullying é reconhecido como um problema de saúde, em decorrência das consequências negativas que podem inferir no desenvolvimento dos estudantes, além de ser fator de risco para violência institucional e social. No sexto capítulo, "Medidas de Bullying estado da arte", Altemir José Gonçalves Barbosa, Juliana Célia de O liveira, Karen Cristina Alves Lamas e Nelimar Ribeiro de Castro indicam uma tendência de crescimento no número de pesquisas sobre 0 tema, principalmente na área da Educação, e apontam a necessidade de mais estudos psicométricos 
para evidenciar a qualidade dos instrumentos de medida para esse construto.

A motivação para apreender segundo as teorias de Metas e Realizações e de Autodeterminação é o foco do sétimo capítulo, escrito por Acácia Aparecida Angeli dos Santos, Adriana Rosecler Alcará e Rebecca de Magalhães Monteiro, intitulado "A motivação para aprender na perspectiva da Teoria de Metas e Realização e Teoria da Autodeterminação". As autoras objetivaram analisar periódicos científicos de psicologia anline do período de 2001 a 2010. Esse estudo evidenciou a necessidade de mais pesquisas nacionais para a construção de escalas padronizadas que considerem as características dos alunos por ano escolar.

As pessoas buscam compreender a causalidade de eventos ocorridos no seu cotidiano a fim de, futuramente, poder prever ou modificar seus efeitos. A avaliação das atribuições de causalidade no contexto escolar é importante para detectar a percepção dos estudantes diante de algumas circunstâncias acadêmicas, como sucesso e fracasso. Desse modo, Danielle Ribeiro Ganda e Evely Boruchovitch, no oitavo capítulo, "Avaliação da atribuição de causalidade em contexto educacional", apresentam uma revisão da literatura sobre esse tema e descrevem os principais instrumentos de medidas nacionais e internacionais sobre esse construto, considerando as qualidades psicométricas, e realizam uma discussão sobre a forma da avaliação do mesmo.

A segunda parte do livro reúne tópicos sobre a avaliação psicológica no contexto psicossocial. O nono capítulo, "Instrumentos de avaliação utilizados com agressores sexuais", é escrito por D enise Müller Böhm e Vera Lúcia Marques de Figueiredo a respeito de uma temática pouco discutida no país, a avaliação do grupo clínico, abusadores ou agressores sexuais. 0 texto não tem como foco um único construto, mas sim discorrer sobre os aspectos pertinentes ao comportamento e quais instrumentos são usualmente utilizados para avaliação desse grupo. As autoras relatam os desafios e direções para futuras pesquisas sobre a temática.

Nelson Hauck Filho e Marco Antonio Pereira Teixeira apresentam, no décimo capítulo, "Instrumentos psicométricos de avaliação da personalidade psicopática: uma revisão da literatura nacional e internacional", uma revisão sistemática da literatura dos principais instrumentos destinados à avaliação da personalidade psicótica. Os autores fazem uma apreciação crítica sobre a definição do construto e as formas de mensuração, indicando também algumas limitações quanto às evidências de validades dos testes.

Mediante aos altos índices de prevalência dos sintomas depressivos na sociedade atual, no décimo primeiro capítulo, "Escalas de avaliação de sintomas depressivos", Makilim Nunes Baptista, Irani Iracema de Lima Argimon e Elisa Medici Pizão Yoshida discorrem sobre a temática e sua forma de avaliação. Por meio de uma revisão sistemática da literatura, os autores apontam os seis instrumentos utilizados com maior frequência para mensurar depressão e descrevem suas propriedades psicométricas. Trazem, também, uma reflexão dos desafios existentes e direção para novas pesquisas.

Dentre as variáveis psicológicas avaliadas no contexto do trânsito, o construto atenção sempre esteve presente na história da psicologia do trânsito no Brasil. O décimo segundo capítulo, "Avaliação da atenção no contexto da psicologia do trânsito: análise das publicações na área", de Fabián Javier Marín Rueda e Rebecca de Magalhães Monteiro, visou analisar a produção científica brasileira referente ao fenômeno atenção entre os anos de 2001 e 2011. Os autores enfatizam a insuficiência de pesquisas na última década, em que se obtiveram apenas sete publicações sobre 0 tema em periódicos nacionais. Foram analisados também os estudos psicométricos pertinentes aos instrumentos que avaliam a atenção e contatou-se que nenhum estudo apresentou evidências de validade de critério. É feita uma reflexão sobre o momento atual da avaliação psicológica no trânsito e os obstáculos a serem suplantados.

A avaliação da autoeficácia é o assunto do décimo terceiro capítulo, de Soely Aparecida Jorge Polydoro, Diana Aguiar Vieira, Roberta Gurgel Azzi e Marilda Dantas, intitulado "Avaliação da autoeficácia no domínio da carreira", sendo este o último capítulo da segunda parte do livro. As autoras conceituam a autoeficácia com base na Teoria Social Cognitiva e esclarecem as terminologias subjacentes ao construto. Elas realizaram uma pesquisa de levantamento da produção científica em publicações internacionais e nacionais da última década acerca desse tema. A análise dos instrumentos foi agrupada sob dois aspectos, a autoeficácia para conteúdos específicos em termos de área formativa e a autoeficácia voltada para os processos que permeiam qualquer formação profissional. Por fim, são apontados os desafios e avanços da avaliação psicológica para autoeficácia sob a perspectiva da Teoria Social Cognitiva.

O livro Avaliação psicdógica nos contextos ectucativo e psicosscial é resultante dos investimentos do grupo de trabalho "Pesquisa em Avaliação Psicológica", da Associação Nacional de Pesquisa e Pós-Graduação em Psicologia (ANPEPP), que oferece ao leitor informações relevantes sobre a avaliação psicológica, a qualificação dos instrumentos de medida, elucida os desafios e avanços percorridos na avaliação nos últimos 
dez anos e proporciona a visão do cenário atual da avaliação de ambos os contextos. Faz-se fonte relevante para profissionais, pesquisadores e estudantes que estejam envolvidos com tais temáticas e contribui para maior esclarecimento e apreciação do estado da arte na avaliação psicológica.

Sobre a autora:

Juliana Maximila de Paula Bueno é psicóloga e mestranda do Programa de Pós-Graduação Strido Sensu em Psicologia da Universidade São Francisco, e bolsista do O bservatório da Educação - O beduc/ Capes/ Inep.

Contato com a autora:

Alameda das Sucupiras, 114 - Caxambu - CEP 13216-777 - Jundiaí-SP.

E-mail: julianampbueno@ hotmail.com 